\title{
A novel simulation competition format as an effective instructional tool in post-graduate medical education
}

\author{
Pier Luigi Ingrassia ${ }^{1,3^{*}}$, Jeffrey Michael Franc ${ }^{2}$ and Luca Carenzo
}

\begin{abstract}
Objective: Medical simulation competitions are a growing reality. This study aims at exploring if a novel format of simulation competition (SIMCUP) can be an effective educational format in post-graduate education.

Design: We designed a 2-day event that included scientific educational lectures, an orientation to the competition, familiarization with the simulation lab, and competition time. Day 1 was devoted to preliminary rounds and was structured using an Objective Structured Clinical Examination (OSCE)-like system. On day 2, the first four teams advanced to semi-finals and then to finals, which were held using a classical SimWars style.

Setting and subjects: A total of 14 four-participant teams participated in the event over two editions (Ed.1 in 2015 and Ed.2 in 2016).

Interventions: External referees evaluated both technical and non-technical skills for each simulated scenario. Each participant was also administered pre- and post-test questionnaires covering self-perception about the confidence in managing simulated clinical cases, educational effectiveness, satisfaction with the simulation experience, and previous simulation training.
\end{abstract}

Main results: Overall participants found SIMCUP a useful learning experience, rating it $10[9,10]$ and 10 [7.75-10] out of 10 for Ed.1 and Ed.2, respectively. Participants reported, using a 10-point semantic differential scale ranging from "1 - strongly disagree." to "10 - strongly agree," finding both days to be educationally effective: day 1 was rated 9 [7-10] and 9 [8-10] as day 2 was rated 8 [7-10] and 8 [7-10] for Ed. 1 and Ed. 2, respectively.

Participants' self-perception regarding the confidence of managing the specific scenarios significantly improved immediately after the event as measured by pre- and post-questionnaires for all stations and during both editions.

Conclusion: This study suggests that simulation competition can serve as an effective instructional format in residency training.

Keywords: Medical simulation, Simulation competition, SIMCUP, Residents, Trainees, SimWars, Post-graduate education

\section{Background}

The benefits of simulation-based training in residents' education have been recently well described [1-5]. It has been demonstrated that simulation can meet the general educational goals of transfer of knowledge, strengthening

\footnotetext{
*Correspondence: pierluigi.ingrassia@med.uniupo.it

${ }^{1}$ SIMNOVA - Centro Interdipartimentale di Didattica Innovativa e di Simulazione in Medicina e Professioni Sanitarie, Università del Piemonte Orientale, Via Lanino 1, 28100 Novara, Italy

${ }^{3}$ SIMNOVA - Centro Interdipartimentale di Didattica Innovativa e di Simulazione in Medicina e Professioni Sanitarie, Università del Piemonte Orientale, Via Lanino 1, 28100 Novara, Italy

Full list of author information is available at the end of the article
}

of cognitive strategies [6], and skill development [7] while adding a dimension of team training [8]. By focusing on adult learning theories, simulation offers its learners deliberate practice and experiential learning [9]. Moreover, training that employs simulation technologies could serve as an important adjunct to learning in the setting of reduced practical exposure due to the reduction in resident work hours globally [10-12]. Excellence in professional development is dependent on time available to practice, motivation, and perseverance [13].

An important change in resident medical education is the arrival of millennial students. To ensure success, 
medical educators need to know and accept the unique characteristics of these new learners: they often prefer to work in groups with hands-on experiences, enjoying trial and error [14]; they frequently expect learning to be interactive, creative, and fun; they often enjoy thinking laterally [15]. The use of gamification is becoming more and more popular to motivate teaching and learning, also in the medical field [16]. Gamification is the process by which users are encouraged and enticed to perform tasks by incorporating elements of game design and competition. Inherent reward and enjoyment can foster motivation. The effectiveness of competition in medical education has been well supported in the literature [17-19]. It has also been documented that competition can boost residents' engagement in simulation training [20].

Onstage competitions, called SimWars, are now very popular in multiple specialties. In the SimWars, two teams perform the same scenario to the jury and the audience. Either the referee panel or an audience vote determines which team moves on to the next round of competition [21]. SimWars have been demonstrated to be effective for resident training and helpful for professional development $[22,23]$. Taking inspiration from the SimWars, we modified the competition format and designed a simulation competition for residents with the aim of engaging participants to partake in deliberate practice and to experiment using different types of simulations and simulators. We postulated that simulation competition can have an educational value and not only be a mere competitive game. The manuscript describes our 2-year experience with SIMCUP (SIMULATION CUP) and its grounding pedagogical and educational rationales. The objective of this study is to present the new format of simulation competition and to investigate whether the new format was perceived, by the participants, to be an effective educational experience.

\section{Methods}

The study took place at the SIMNOVA Simulation Center based at the Università del Piemonte Orientale in Novara, Italy. The study was submitted to the local ethics committee, which reviewed it and awarded an exemption letter (prot. 713/CE). Each participant was informed about data collection and signed a consent form about audio-video and data collection. This manuscript was prepared following the recommendations of the reporting guidelines for healthcare simulation research [24].

\section{Competition design}

The competition was designed as a 2-day event that included scientific educational lectures, an orientation to the competition, familiarization with the simulation lab, and competition time. Day 1 was devoted to preliminary rounds and was structured using an Objective Structured Clinical Examination (OSCE)-like system [25]. The first day included six simulation stations in which each team was expected to perform a variety of clinical tasks within a given time period (10 min). Evaluation was performed using predetermined criteria formulated to demonstrate competency of skills and attitudes. A seventh station in the form of a technical skill fair gave the participants the opportunity to test their own abilities and manual skills in different areas. At the end of day 1 , the four highest ranking teams moved on to the semifinals. On Day 2, semi-finals and finals were held using a classical SimWars style. The semi-finalists and finalists performed their simulation in front of the audience consisting of those teams who did not qualify for the finals, the faculty, and the judges. To keep the final simulations secret, the semifinals and final teams were confined to a room away from the main simulation stage. A detailed description of day 1 and day 2 stations is presented in Table 1.

At the end of each simulation, a debriefing was carried out. Day 1 simulations were followed by facilitator-led individual team debriefing, while during day 2 , each final scenario was followed by a plenary critical reflection with a public interaction between the facilitators and the participating teams. Facilitators were the same instructors running each simulation station and final scenario. SIMCUP can be resource intensive especially from the human resource aspect. We planned a ratio of facilitator/instructor to participant around 1:2.5. The facility allowed ten simultaneous simulation sessions to be carried out. Instructors volunteered their time during SIMCUP.

\section{Population}

SIMCUP was open to residents from any Italian residency program and from any level of training. Participants voluntarily signed up for the event. Four members composed each team and multidisciplinary team were encouraged. The first edition of SIMCUP was conducted in 2015 (Ed. 1) and the second one in 2016 (Ed. 2) with the program still going on today.

\section{Endpoints}

This is a descriptive study centered on participant's satisfaction, participant's self-perception of effectiveness, and knowledge gain. We used the first two of Kirkpatrick's four levels of evaluation to assess this. Kirkpatrick's tool is a model for assessing training programs. The first level explores participants' satisfaction with the training program: overall event quality, satisfaction with the simulation, and effectiveness of the training format. The second expresses the knowledge gain obtained with the educational process measured as difference between pre- 
Table 1 Title, type, and simulator used and scenarios played at each station for both editions of SIMCUP

\begin{tabular}{|c|c|c|c|c|c|}
\hline Station & Title & Type & Edition & Simulator & Scenario \\
\hline \multicolumn{6}{|l|}{ Day 1} \\
\hline \multirow[t]{2}{*}{1} & \multirow[t]{2}{*}{ Medical adult } & \multirow[t]{2}{*}{ High fidelity } & 2015 & \multirow[t]{2}{*}{ Gaumard HAL S3201 } & Acute pulmonary edema \\
\hline & & & 2016 & & Acute upper Gl bleeding \\
\hline \multirow[t]{2}{*}{2} & \multirow{2}{*}{$\begin{array}{l}\text { Advanced cardiac } \\
\text { life support }\end{array}$} & \multirow[t]{2}{*}{ Medium fidelity } & 2015 & \multirow[t]{2}{*}{ Laerdal ALS Simulator } & \multirow[t]{2}{*}{ Cardiac arrest following hyperkalemia } \\
\hline & & & 2016 & & \\
\hline \multirow[t]{2}{*}{3} & \multirow[t]{2}{*}{ Disaster triage } & \multirow[t]{2}{*}{ Virtual reality } & 2015 & \multirow[t]{2}{*}{ e-semble XVR } & $\begin{array}{l}\text { Triage of ten casualties following motor } \\
\text { vehicle accident }\end{array}$ \\
\hline & & & 2016 & & Triage of ten casualties following train accident \\
\hline \multirow[t]{2}{*}{4} & \multirow[t]{2}{*}{ Pediatric/neonatal } & \multirow[t]{2}{*}{ High fidelity } & 2015 & \multirow[t]{2}{*}{ Laerdal SimBaby } & Birth asphyxia \\
\hline & & & 2016 & & Dehydration and hypoglicemia in a small children \\
\hline \multirow[t]{2}{*}{5} & \multirow[t]{2}{*}{ Obstetric emergency } & \multirow[t]{2}{*}{ High fidelity } & 2015 & \multirow[t]{2}{*}{ Gaumard Noelle S57x.100 } & Eclampsia \\
\hline & & & 2016 & & Post-partum hemorrhage \\
\hline \multirow[t]{2}{*}{6} & \multirow[t]{2}{*}{ Pre-hospital trauma } & \multirow[t]{2}{*}{ High fidelity } & 2015 & Gaumard HAL S3101 & Traumatic lower limb amputation with shock \\
\hline & & & 2016 & Standardized Patient & $\begin{array}{l}\text { Open fracture of the lower limb with active bleeding } \\
\text { from femoral artery }\end{array}$ \\
\hline \multirow[t]{2}{*}{$7 a$} & \multirow{2}{*}{$\begin{array}{l}\text { Emergency } \\
\text { bronchoscopy }\end{array}$} & \multirow[t]{2}{*}{ Skill station } & 2015 & Simbionix Bronch Mentor & \multirow[t]{2}{*}{ Removal of a foreign body } \\
\hline & & & 2016 & Airway Ldt Orsim & \\
\hline \multirow[t]{2}{*}{$7 b$} & Lumbar puncture & Skill station & 2015 & Kyoto Kagaku Lumbar & Lumbar puncture execution \\
\hline & & & 2016 & Puncture Simulator II & \\
\hline $7 c$ & FAST ultrasound & Skill station & 2015 & Standardized patient & FAST execution \\
\hline & & & 2016 & 3DSystem U/S Mentor & \\
\hline $7 d$ & Basic surgical skill & Skill station & 2015 & Basic Surgical Instruments and & Suture execution \\
\hline & & & 2016 & & \\
\hline $7 e$ & Ultrasound guided & Skill station & 2015 & SimuLab Central Line System & Placement of central venous line under US guidance \\
\hline & cve placement & & 2016 & & \\
\hline $7 f$ & Quality CPR & Skill station & 2015 & Laerdal QCPR ResusciAnne & $\begin{array}{l}\text { Achievement of perfection in chest compression } \\
\text { rate and timing }\end{array}$ \\
\hline & Chest drain placement & & 2016 & SimuLab Trauma Man System & Chest drain placement \\
\hline Day 2 & & & & & \\
\hline Semi-finals & Adult & High fidelity & 2015 & Gaumard HAL S3201 & Traumatic brain injury \\
\hline & Obstetric emergency & & 2016 & Gaumand Noelle S57x.100 & Domestic violence in a 33-week pregnant lady \\
\hline & Pediatric/neonatal & & 2016 & Laerdal SimBaby & Congenital diaphragmatic hernia \\
\hline Finals & Obstetric emergency & High fidelity & 2015 & $\begin{array}{l}\text { Gaumard Noelle S57x.100 } \\
\text { Laerdal SimBaby }\end{array}$ & $\begin{array}{l}\text { Cardiac arrest with peri-mortem C-section } \\
\text { and neonatal resuscitation }\end{array}$ \\
\hline & Adult & & 2016 & Gaumard HAL S3201 & $\begin{array}{l}\text { Acute anaphylaxis with complete airway obstruction } \\
\text { and need for surgical airway in an outpatient settings }\end{array}$ \\
\hline
\end{tabular}

and post-event assessment of participant confidence in managing specific critical scenarios [26].

Moreover, technical and non-technical skill performance was quantitatively measured for each simulation scenario.

\section{Participants self-perception and feedback}

On day 1, participants were asked to fill out a paper-based questionnaire about (1) demographics including previous training specifically organized for the simulation competition and (2) baseline self-perceived levels of confidence in managing critical care scenarios. Participants were then invited to fill out a second electronic questionnaire 1 week after the competition. The questionnaire consisted of the following content sections: (1) overall appreciation of the competition, the format, and stressfulness of the simulations; (2) satisfaction with the simulation experience; (3) effectiveness of the training format; and (4) self-perceived levels of confidence in managing critical care cases after the simulation experience. 
For the section about satisfaction with the simulation experience, the previously validated Satisfaction with Simulation Experience Scale (SSES, a 5-item Likert scale) was used [27, 28]. For the other sections, responders were asked to reply using a 10-point semantic differential scale ranging from "1 - strongly disagree" to "10 - strongly agree."

\section{Performance assessment}

Two or three raters at each station judged team performance. The case designers developed a technical skills scoring sheet for each simulation scenario with a predetermined maximum score. These scoring sheets were simple checklists scored as 0 (no), 2 (yes), or 1 (yes, but incomplete). The total sum of each checklist was then transformed in a decimal score ranging from 0 to 1 by means of dividing the achieved score by the maximal theoretical score. Non-technical skills were measured using either the English or the Italian version of the global rating scale (GRS), which includes six items ranging from 0 to 7 with a maximum possible score of $42[29,30]$. All raters were experts in critical and emergency care and were the same in both editions of the competition. All raters were familiar users of the assessment tools and participated in a pre-event briefing regarding assessment procedure. All measurements composed the final ranking score and served for the competition progression.

\section{Statistical analysis}

Descriptive statistics were summarized using median and percentiles. Pre-post-competition differences in self-perception regarding confidence were tested using the Wilcoxon signed-rank test.

\section{Results}

A total of seven different teams registered to each of the two events. Demographics of the participants are presented in Table 2.

\section{Overall appreciation, satisfaction with simulation, and educational effectiveness}

Overall participants found the SIMCUP as a useful learning experience, rating it globally $10[9,10]$ and 10 [7.75-10] out of 10 for Ed.1 and Ed.2, respectively.

The global results for the Satisfaction with Simulation Experience Scale were $4[3-5]$ and $5[4,5]$ out of 5 for Ed. 1 and Ed. 2, respectively.

Educational effectiveness of each topic as rated by participants is presented in Table 3. Regarding methodologies, all participants from both years reported finding both days to be educationally effective: the OSCE-like format of day 1 nine [7-10] and 9 [8-10] as well as the SimWars-like format of day 2 eight [7-10] and 8 [7-10]
Table 2 Demographics of event participants per edition

\begin{tabular}{lll}
\hline & $\begin{array}{l}\text { Ed.1 } \\
n=28(\%)\end{array}$ & $\begin{array}{l}\text { Ed.2 } \\
n=28(\%)\end{array}$ \\
\hline Age (mean), year & 30 & 30 \\
Female gender & $14(50)$ & $16(57)$ \\
Residency training year & & \\
PGY1 & $5(18)$ & $1(4)$ \\
PGY2 & $8(29)$ & $10(36)$ \\
PGY3 & $6(21)$ & $5(18)$ \\
PGY4 & $7(25)$ & $4(14)$ \\
PGY5 & $2(7)$ & $8(29)$ \\
Training program & & \\
Anesthesia/critical care & $17(61)$ & $12(43)$ \\
Emergency medicine & $7(25)$ & $9(33)$ \\
Geriatrics & $0(0)$ & $3(11)$ \\
Internal medicine & $2(7)$ & $2(7)$ \\
Pediatrics & $0(0)$ & $1(4)$ \\
Cardiology & $2(7)$ & $1(4)$ \\
\hline
\end{tabular}

$P G Y$ post-graduate year

for Ed1 and Ed2, respectively. Participants self-rated their stress level during the simulations as 8 [7-10] for Ed.1 and 8.5 [6-10] out of 10 for Ed.2.

\section{Participant's confidence in managing critical scenario}

Participants' self-perception regarding the confidence of managing the specific scenarios significantly improved immediately after the event as measured by pre and post-questionnaires for all stations and during both editions. Global self-perception about the level of confidence in managing the cases improved from 4 [3-5] to 6 [4-7] in Ed.1 $(p<0.05)$ and from 5 [3-6] to 7 [5-8] in Ed. $2(p<0.05)$ out of a scale of 10 .

Details about each station are presented in the Additional file 1 while the detailed variation between pre- and post-event for each simulation station is represented in Fig. 1.

Table 3 Educational effectiveness of each simulation scenario/ topic as rated by participants using a 10-point unanchored semantic scale. Results presented as median and 25-75 percentile

\begin{tabular}{lll}
\hline & Ed.1 & Ed.2 \\
\hline High fidelity, medical adult (1) & $9[8-10]$ & $9[8-10]$ \\
Medium fidelity, ACLS (2) & $8[5-10]$ & $9[7-10]$ \\
Virtual reality, disaster triage (3) & $6[3-8]$ & $8[7-9.25]$ \\
High fidelity, pediatric/newborn (4) & $9[5-10]$ & $9.5[7-10]$ \\
High fidelity, obstetrical emergency (5) & $8[6-9]$ & $8[6.75-10]$ \\
High fidelity, pre-hospital trauma (6) & $9[7-10]$ & $9.5[8-10]$ \\
\hline
\end{tabular}




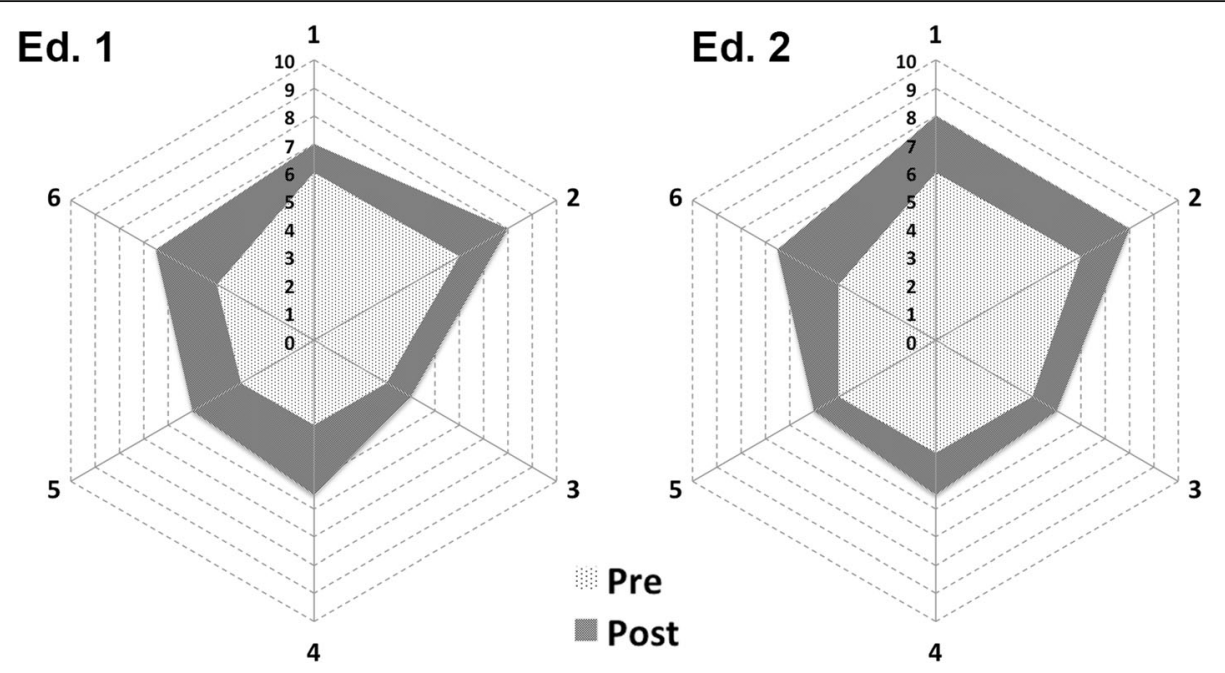

Fig. 1 Radar charts presenting median self-confidence perception level variation before (dotted white) and after (gray) the event. Apexes of the polygon represent each simulation station (1 medical adult, 2 advanced cardiac life support, 3 disaster triage, 4 pediatric/neonatal, 5 obstetric emergency, 6 pre-hospital trauma). Axes in each radar chart represent the 10-point Likert scale

\section{Performance assessment}

Performance was homogenous between participants of both editions. Details for each station are presented in the Additional file 1. Post hoc visual inspection of team assessment plots (presented in the Additional file 1) between non-technical skills versus technical skills suggests a possible stronger correlation between the two when human factor skills, measured by GRS, are either very high or very low.

\section{Training}

Five teams out of 7 (71\%) from Ed.2 reported that they organized some sort of training before attending the event. All five teams reported paper-based study as well as low-fidelity simulation training (BLS Mannequins, homemade simulators), while only 3 teams reported training in a medium to high-fidelity setting. Training data were not collected in Ed. 1.

\section{Discussion}

This study suggests that the proposed simulation competition format is both perceived educationally effective and can improve self-confidence in participating trainees. This suggests it might be a meaningful instructional format to educate residents in clinical management, psychomotor abilities and communication, and teamwork skills.

To our knowledge, the event represents the first training format involving residents from many different Italian residency programs throughout the country, as well as from several different specialties broadly related to critical care. Residents were able to practice their skills and demonstrate abilities in a competitive yet controlled environment, and develop collegiality and teamwork.
The majority of residents reported very high satisfaction both with the event in general as well as with simulation experience measured with the SSES. Although originally developed by nursing researchers, the SSES is generic in nature, allowing its use in other health-related discipline studies. It addresses different aspects of the simulation experience, such as facilitators, debriefing, and reflection, and connects them to clinical reasoning. Residents showed high levels of satisfaction in the SSES, and these results are very important in terms of professional development and clinical performance. Participant satisfaction has been associated with greater involvement in the process and greater motivation for learning [31]. Thus, the participants' satisfaction may be a good measure to evaluate the teaching and the educational format itself as well [32].

When asked about the level of self-perceived confidence and proficiency before and after participation in the competition, surveyed residents reported a significant improvement in their self-perceived confidence and proficiency. It is known that self-confidence is an important mediating factor that contributes to the extent to which one approaches learning and persists towards achievement of goals and expertise [33]. In addition, previous studies suggest a correlation between experience and self-perceived competence [34-36].

Our findings suggest that a competitive yet controlled simulation environment is a positive learning experience. This is consistent with previous studies, which highlight how the competitive nature of such events provides opportunities for participants to mature in the psychomotor and affective domains of adult learning [17, 19, 37]. Even the competition-induced stress plays as positive role, as 
stressful situations improve knowledge retention and, up to a certain level, performance [38, 39]. For high-stress professions, such as critical care physicians, training under close-to-real stressful settings helps future practice. Previous literature suggests that stress during competition can have a beneficial effect to participants [23].

The SIMCUP incorporated several learning theories into one event to maximize education. All residents had the opportunity to experience simulated clinical cases in the preliminary rounds of day 1 . On day 2 , those who were not directly involved in the competition on stage were able to observe the process. This allowed them all to apply their previously acquired competencies in the clinical setting and to learn from both achievement and errors. A number of recently published educational articles expand Kolb's original work on experiential learning, which stated that learning is the process whereby knowledge is created through the transformation of experience [40].

All SIMCUP participants began by completing a simulated critical event (first phase of Kolb's cycle). They then came together for structured debriefing: reflective observation and analysis of a concrete experience were carried out through participants' narrations, questions, and statements with reference to relevant experienced problems and situations that occurred during the simulated event (second phase). These reflections were then assimilated as abstract concepts from which new implications for action were drawn (third phase). These new implications could be actively and immediately experimented and tested in the following simulated event in the circuit (fourth phase).

Observational learning is considered one of the most powerful learning mechanisms [41]. SIMCUP participants were not only able to practice themselves but also watch and observe other team practicing and performing. This is particularly important especially for those teams who did not qualify on day 2 and did not have a chance to be hands-on on the second day. They had however the chance to reflect on other teams' actions by examining and observing other team simulations and participating in plenary debriefing. SIMCUP combined individual skill assessment with group-learning format. Effective teams work towards a goal by using shared knowledge and skills, aligning with social constructivism theory, which recognizes the value of social interactions in the learning process [42]. The provision of a simulation gives learners a sense of immediacy and involvement where time and the chosen response are critical to successful outcomes [43].

The performance evaluation allowed assessment of technical and non-technical skills that might deserve a corrective intervention. Participants performed poorly in the station related to management of mass casualty events, pointing out a weakness in the residents' knowledge. This reflects the similar and wider situation at the national level. A recent study conducted on a sample of Italian hospitals revealed that not every assessed hospital had a formal training program (e.g., drills, simulations, cross-training in high-demand services) for health-care providers [44]. Promoting and enhancing the training capacity in the field of disaster medicine is one of the "call-to-action requirements" requested by the international community [45]. Teams of both editions of the competition also scored poorly at the obstetrical emergency station, particularly Ed 1. This is no surprise, as obstetrical emergencies are known to commonly induce intense stress [46].

Nowadays, increased alertness is directed towards non-technical skills as an essential component of optimal management of emergencies [47]. Our findings regarding team performance suggests that teams who are very strong in non-technical skills also appear to be very strong in technical skills, and the same may be true for very weak teams. A similar correlation has been shown in previous research $[48,49]$. Conversely, teams in the mid-scale have much more variable technical abilities. This finding may also suggest that in this setting, simulation performance requires assessment of both technical and non-technical skills.

\section{Limitations}

There are several limitations to this study. Due to the practicalities of event, registration teams had heterogeneous post-graduate training experience and skill-set; however, this also might happen in real life. Some results rely on the self-assessment of the residents who were queried, which is not always an accurate indicator of actual competence. Whether the increase in self-confidence that residents report actually translates to improved performance in clinical medicine and subsequent patient outcomes is beyond the scope of this study and would be an interesting follow-up study. Moreover, a participant selection bias may apply as residents who do not thrive to participate in such events might not achieve the same results and might not find this educational format suitable to their needs.

Second, it remains to be seen if these results can be generalized to other medical specialties and settings beyond the ones in the present study.

Finally, it is important to recognize that the SIMCUP is a very intensive but brief learning experience. As such, the educational benefits to participants may be limited by this short encounter time.

\section{Conclusion}

This study suggests that simulation competition may serve as a relevant instructional format in residency training. Residents were able to practice their skills and demonstrate abilities in a competitive yet controlled 
environment while experiencing and developing clinical management skills, psychomotor abilities, communication strategies, and teamwork skills. The performance assessment method allowed delineation of both the clinical areas and the skills, in terms of technical and non-technical, which deserve a corrective intervention.

The surveyed residents reported high satisfaction with simulation experience and a greater improvement of self-perceived competency and proficiency.

\section{Additional file}

Additional file 1: Self-perceived confidence results for each station before and after each event (10-item Likert scale). Results are median and 25-75 percentile. Performance assessment score for each station regarding both skill scores and non-technical skills--global rating scale (GRS). Skill scores range from 0 to 1 while GRS from 0 to 42. Results are median and 25-75 percentile. Relationship between technical skill score (at in this chart) and non-technical skill score GRS (overall in this chart) for each team in each station. (DOCX $29 \mathrm{~kb}$ )

\section{Acknowledgements}

We would like to thank all the referees and instructors who dedicated their time and energy to take part in the two editions of the SIMCUP and provided invaluable input for its success. We are aiming at keeping SIMCUP running for the longest time possible.

\section{Funding}

This study is the author's independent own work. No financial support was received for the conduction of this study. No authors received any compensation for the present study neither for participation in SIMCUP.

\section{Availability of data and materials}

All data generated or analyzed during this study are included in this published article (and its supplementary information files).

\section{Authors' contributions}

PLI and LC designed the simulation format and organized the events. JF collected the data and performed the statistical analysis. All authors significantly contributed in writing and approved the final manuscript.

\section{Ethics approval and consent to participate}

The study was submitted to the Comitato Etico Interaziendale di Novara (http://www.comitatoeticonovara.it/), which reviewed it and awarded an exemption letter (protocol number 713/CE).

\section{Consent for publication}

Not applicable

\section{Competing interests}

The authors declare that they have no competing interests.

\section{Publisher's Note}

Springer Nature remains neutral with regard to jurisdictional claims in published maps and institutional affiliations.

\section{Author details}

'SIMNOVA - Centro Interdipartimentale di Didattica Innovativa e di Simulazione in Medicina e Professioni Sanitarie, Università del Piemonte Orientale, Via Lanino 1, 28100 Novara, Italy. ${ }^{2}$ Department of Emergency Medicine, University of Alberta, 790 University Terrace Building, 8303 - 112 Street, Edmonton, AB T6G 2T4, Canada. ${ }^{3}$ SIMNOVA - Centro Interdipartimentale di Didattica Innovativa e di Simulazione in Medicina e Professioni Sanitarie, Università del Piemonte Orientale, Via Lanino 1, 28100 Novara, Italy.
Received: 23 March 2018 Accepted: 11 July 2018

Published online: 09 August 2018

\section{References}

1. Balki M, Chakravarty S, Salman A, Wax RS. Effectiveness of using high-fidelity simulation to teach the management of general anesthesia for cesarean delivery. Can J Anaesth. 2014;61(10):922-34.

2. You-Ten KE, Bould MD, Friedman Z, Riem N, Sydor D, Boet S. Cricothyrotomy training increases adherence to the ASA difficult airway algorithm in a simulated crisis: a randomized controlled trial. Can J Anaesth. 2015;62(5):485-94.

3. Siddiqui NT, Arzola C, Ahmed I, Davies S, Carvalho JCA. Low-fidelity simulation improves mastery of the aseptic technique for labour epidurals: an observational study. Can J Anaesth. 2014;61(8):710-6.

4. Leblanc VR. Review article: simulation in anesthesia: state of the science and looking forward. Can J Anaesth. 2012;59(2):193-202.

5. Allen GB, Miller V, Nicholas C, Hess S, Cordes MK, Fortune JB, et al. A multitiered strategy of simulation training, kit consolidation, and electronic documentation is associated with a reduction in central line-associated bloodstream infections. Am J Infect Control. 2014;42(6):643-8.

6. Bond WF, Deitrick LM, Arnold DC, Kostenbader M, Barr GC, Kimmel SR, et al. Using simulation to instruct emergency medicine residents in cognitive forcing strategies. Acad Med. 2004;79(5):438-46.

7. Steadman RH, Coates WC, Huang YM, Matevosian R, Larmon BR, McCullough $\mathrm{L}$, et al. Simulation-based training is superior to problem-based learning for the acquisition of critical assessment and management skills. Crit Care Med. 2006;34(1):151-7.

8. Marshall SD, Flanagan B. Simulation-based education for building clinical teams. J Emerg Trauma Shock. 2010;3(4):360-8.

9. Zigmont JJ, Kappus $\sqcup$, Sudikoff SN. Theoretical foundations of learning through simulation. Semin Perinatol. 2011;35(2):47-51.

10. Jamal MH, Wong S, Whalen TV. Effects of the reduction of surgical residents work hours and implications for surgical residency programs: a narrative review. BMC Med Educ. 2014;14(Suppl 1):S14.

11. Nasca TJ, Day SH, Amis ES, ACGME Duty Hour Task Force. The new recommendations on duty hours from the ACGME Task Force. N Engl J Med. 2010;363(2):e3.

12. The members of the ACGME Task Force on Quality Care and Professionalism. The ACGME 2011 duty hour standard: enhancing quality of care, supervision and resident professional development. 2011. Available from: https://www.acgme.org/Portals/0/PDFs/jgme-monograph\%5B1\%5D. pdf. Cited 26 July 2016

13. Ericsson KA, Krampe RT, Tesch-Römer $C$. The role of deliberate practice in the acquisition of expert performance. Psychol Rev. 1993;100(3):363-406.

14. Mangold K. Educating a new generation: teaching baby boomer faculty about millennial students. Nurse Educ. 2007;32(1):21-3.

15. Eckleberry-Hunt J, Tucciarone J. The challenges and opportunities of teaching "generation y". J Grad Med Educ. 2011;3(4):458-61.

16. Nevin CR, Westfall AO, Rodriguez JM, Dempsey DM, Cherrington A, Roy B, et al. Gamification as a tool for enhancing graduate medical education. Postgrad Med J. 2014;90(1070):685-93.

17. Weng $Y-H$, Kuo KN, Yang C-Y, Liao $H-H$, Chen C, Lo H-L, et al. Effectiveness of national evidence-based medicine competition in Taiwan. BMC Med Educ. 2013;13(1):66.

18. Morritz T, Seehafer RW, Maatz-Majestic E. A student competition to develop an innovative alcohol education strategy. J Am Coll Heal. 1993;41(6):283-6.

19. Htwe TT, Sabaridah I, Rajyaguru KM, Mazidah AM. Pathology crossword competition: an active and easy way of learning pathology in undergraduate medical education. Singap Med J. 2012;53(2):121-3.

20. Kerfoot BP, Kissane $N$. The use of gamification to boost residents' engagement in simulation training. JAMA Surg. 2014;149(11):1208

21. Okuda Y, Godwin SA, Jacobson L, Wang E, Weingart S. SimWars. J Emerg Med. 2014:47(5):586-93.

22. Dong C, Clapper TC, Szyld D. A qualitative descriptive study of SimWars as a meaningful instructional tool. Int J Med Educ. 2013;4:139-45.

23. Dong C, Goswami R, Sim GG, Kowitlawakul Y. Emergency medicine staff's perception of SimWars: a Singapore view. Proc Singapore Healthc. 2015; 24(3):148-55.

24. Cheng A, Kessler D, Mackinnon R, Chang TP, Nadkarni VM, Hunt EA, et al. Reporting guidelines for health care simulation research: extensions to the CONSORT and STROBE statements. Adv Simul. 2016;1 (1):25. 
25. Zayyan M. Objective structured clinical examination: the assessment of choice. Oman Med J. 2011;26(4):219-22.

26. The New World Kirkpatrick Model. Available from: http://www. kirkpatrickpartners.com/OurPhilosophy/TheNewWorldKirkpatrickModel/tabid/ 303. Cited 26 July 2016

27. Williams B, Dousek S. The satisfaction with simulation experience scale (SSES): a validation study. J Nurs Educ Pract. 2012;2(3):74.

28. Levett-jones T, Mccoy M, Lapkin S, Noble D, Hoffman K, Dempsey J, et al. The development and psychometric testing of the Satisfaction with Simulation Experience Scale. Nurse Educ Today. 2011;31(7):705-10.

29. Kim J, Neilipovitz D, Cardinal P, Chiu M, Clinch J. A pilot study using highfidelity simulation to formally evaluate performance in the resuscitation of critically ill patients: The University of Ottawa Critical Care Medicine, Highfidelity Simulation, and Crisis Resource Management I Study. Crit Care Med. 2006;34(8):2167-74.

30. Franc JM, Verde M, Gallardo AR, Carenzo L, Ingrassia PL. An Italian version of the Ottawa Crisis Resource Management Global Rating Scale: a reliable and valid tool for assessment of simulation performance. Intern Emerg Med. 2017;12(5):651-6.

31. Prion S. A practical framework for evaluating the impact of clinical simulation experiences in prelicensure nursing education. Clin Simul Nurs. 2008;4(3):e69-78

32. Baptista RCN, Martins JCA, Pereira MFCR, Mazzo A. Students' satisfaction with simulated clinical experiences: validation of an assessment scale. Rev Lat Am Enfermagem. 2014;22(5):709-15.

33. Surcouf JW, Chauvin SW, Ferry J, Yang T, Barkemeyer B. Enhancing residents' neonatal resuscitation competency through unannounced simulation-based training. Med Educ Online. 2013;18:1-7.

34. Fincher RM, Lewis LA. Learning, experience, and self-assessment of competence of third-year medical students in performing bedside procedures. Acad Med. 1994;69(4):291-5.

35. Hicks CM, Gonzalez R, Morton MT, Gibbons RV, Wigton RS, Anderson RJ. Procedural experience and comfort level in internal medicine trainees. J Gen Intern Med. 2000;15(10):716-22.

36. Lai NM, Sivalingam N, Ramesh JC. Medical students in their final six months of training: progress in self-perceived clinical competence, and relationship between experience and confidence in practical skills. Singap Med J. 2007; 48(11):1018-27.

37. Cortez EJ, Boulger CT, Eastin T, Adkins EJ, Granitto E, Pollard K, et al. The ultrasound challenge 2.0: introducing interinstitutional competition in medical student ultrasound education. J Ultrasound Med. 2014;33(12):2193-6.

38. Keitel A, Ringleb M, Schwartges I, Weik U, Picker O, Stockhorst U, et al. Endocrine and psychological stress responses in a simulated emergency situation. Psychoneuroendocrinology. 2011;36(1):98-108.

39. Demaria S, Bryson EO, Mooney TJ, Silverstein JH, Reich DL, Bodian C, et al. Adding emotional stressors to training in simulated cardiopulmonary arrest enhances participant performance. Med Educ. 2010:44(10):1006-15.

40. Kolb D. Experiential learning: experience as the source of learning and development. Englewood Cliffs: Prentice-Hall; 1984.

41. van Gog T, Paas F, Marcus N, Ayres P, Sweller J. The mirror neuron system and observational learning: implications for the effectiveness of dynamic visualizations. Educ Psychol Rev. 2009;21(1):21-30.

42. Gibson D, Aldrich C, Prensky M. Games and simulations in online learning: research and development frameworks. Arlington: Information Resources Press; 2007. p.402.

43. Alessi SM, Trollip SR, Alessi SM. Multimedia for learning: methods and development. Boston: Allyn and Bacon; 2001. p. 580.

44. Ingrassia PL, Mangini M, Azzaretto M, Ciaramitaro I, Costa L, Burkle FM, et al. Hospital disaster preparedness in Italy: a preliminary study utilizing the World Health Organization hospital emergency response evaluation toolkit. Minerva Anestesiol. 2016;82:1259.

45. UNISDR (United Nations International Strategy for Disaster Reduction). Sendai framework for disaster risk reduction 2015-2030. Available from: http://www.wcdrr.org/uploads/Sendai_Framework_for_Disaster_Risk_ Reduction_2015-2030.pdf. Accessed 8 Mar 2018.

46. Monod C, Voekt CA, Gisin M, Gisin S, Hoesli IM. Optimization of competency in obstetrical emergencies: a role for simulation training. Arch Gynecol Obstet. 2014;289(4):733-8.

47. Siassakos D, Fox R, Crofts JF, Hunt LP, Winter C, Draycott TJ. The management of a simulated emergency: better teamwork, bette performance. Resuscitation. 2011;82(2):203-6.
48. Riem N, Boet S, Bould MD, Tavares W, Naik VN. Do technical skills correlate with non-technical skills in crisis resource management: a simulation study. $\mathrm{Br}$ J Anaesth. 2012;109(5):723-8.

49. Brunckhorst O, Shahid S, Aydin A, Khan S, Mcllhenny C, Brewin J, et al. The relationship between technical and nontechnical skills within a simulationbased ureteroscopy training environment. J Surg Educ. 2015;72(5):1039-44.
Ready to submit your research? Choose BMC and benefit from:

- fast, convenient online submission

- thorough peer review by experienced researchers in your field

- rapid publication on acceptance

- support for research data, including large and complex data types

- gold Open Access which fosters wider collaboration and increased citations

- maximum visibility for your research: over $100 \mathrm{M}$ website views per year

At BMC, research is always in progress.

Learn more biomedcentral.com/submissions 